\title{
Editorial
}

\section{Update on Nutraceuticals}

\author{
Luisa Tesoriere (1)
}

check for updates

Citation: Tesoriere, L. Update on Nutraceuticals. Nutraceuticals 2021, 1, 1. https://doi.org/10.3390/ nutraceuticals1010001

Received: 13 September 2021 Accepted: 14 September 2021 Published: 16 September 2021

Publisher's Note: MDPI stays neutral with regard to jurisdictional claims in published maps and institutional affiliations.

Copyright: (C) 2021 by the author. Licensee MDPI, Basel, Switzerland. This article is an open access article distributed under the terms and conditions of the Creative Commons Attribution (CC BY) license (https:// creativecommons.org/licenses/by/ $4.0 /)$.
Department of Biological, Chemical, and Pharmaceutical Sciences and Technologies (STEBICEF), University of Palermo, 90128 Palermo, Italy; luisa.tesoriere@unipa.it

Plants provide us with not only nutritional value but have been used throughout history for medicinal purposes. Nutraceuticals is a broad umbrella term that is used to describe any product derived from food sources with extra health benefits in addition to the basic nutritional value found in foods. Nutraceuticals can be products as diverse as isolated nutrients, dietary supplements, herbal products and processed foods. Their beneficial effects can sometimes cause controversy and heated discussions that can only be solved via sound and robust scientific research. The philosophy behind nutraceuticals is to focus on prevention, and their role in human nutrition is one of the most important areas of investigation. The study of nutraceuticals has wide-raging implications for consumers, healthcare providers, regulators, food producers and distributors. We hope that the newly launched journal Nutraceuticals (ISSN: 1661-3821) [1] can act as a platform for researchers to disseminate their findings related to the discovery, development and production of nutraceuticals, with a particular interest in the following topics:

- Natural or Artificial Nutraceuticals;

- Medical Foods/Foods for Special Medical Purposes;

- Nutritional Supplements;

- Dietary Supplements;

- Functional Foods;

- Research and Development of Nutraceuticals;

- Efficiency and Safety of Nutraceuticals;

- Clinical Studies of Nutraceuticals and Biomarkers;

- Production Technologies of Nutraceuticals;

- Mechanisms of Action and Therapeutic Potential of Nutraceuticals;

- Applications of Nutraceuticals Trends and Perspectives.

Nutraceuticals will be published on a quarterly basis and ensure a rigorous and timely peer-review process. We would like to thank all the scholars who have kindly agreed to join us by serving as Editorial Board Members and invite all researchers involved in research on nutraceutical products to submit their reviews, original research papers, communications or case reports and help us develop Nutraceuticals into a top-rated multidisciplinary journal.

Conflicts of Interest: The author declares no conflict of interest.

\section{Reference}

1. Nutraceuticals Home Page. Available online: https://www.mdpi.com/journal/nutraceuticals (accessed on 10 September 2021). 